\title{
Uma propaganda exemplar do governo Lula
}

João Anzanello Carrascoza

Professor doutor do Departamento de Relações Públicas, Turismo

e Publicidade e Propaganda da ECA-USP, professor do Programa de Mestrado em Comunicação

e Práticas de Consumo da ESPM-SP e redator da JWT Publicidade.

E-mail: jcarrascoza@espm.br

\section{COMERCIAL DE TELEVISÃO DO PROUNI': AMOSTRA DA UTILIZAÇÃO DISTORCIDA E PASSADISTA DE REFERÊNCIAS CULTURAIS}

A crítica à publicidade hegemônica em TV, notadamente de produtos de consumo de massa ou serviços para a vida contemporânea, vem ganhando, nas últimas décadas, novas abordagens em obras de importantes estudiosos pelo mundo afora.

No cotidiano brasileiro, especialistas têm refletido sobre a nossa produção televisiva nos seus mais diferentes formatos, como as novelas, os programas de variedades, os reality shows, os telejornais, entre outros, incluindo aí os filmes publicitários.

Contudo, se há espaço para a crítica à propaganda veiculada em televisão, ainda que restrita a comerciais polêmicos, pouca ou quase nenhuma discussão se vê a respeito da propaganda do governo em suas diversas instâncias (federal, estadual e municipal).

O máximo que se nota é um foco de indignação, aqui ou ali, diante de notícias sobre os valores vultosos das verbas governamentais destinadas à propaganda. Ou manifestações isoladas de divergência quanto ao seu conteúdo geral, habitualmente voltado para a prestação de contas à população, muitas vezes com objetivo eleitoreiro.

Em raras oportunidades, produz-se alguma reflexão madura sobre a propaganda deste que é o maior anunciante do País, quando deveria ser prática diária de nossa inteligentzia.

O típico é encontrarmos críticas aos slogans que identificam candidatos a cargos públicos, em especial depois que eles foram eleitos e já exercem suas funções, época em que se torna evidente a falácia, ou mesmo o oportunismo, de sua comunicação eleitoral, acendendo a revolta - passageira, cumpre lembrar - dos formadores de opinião.

É o caso, por exemplo, de slogans como O jeito é Jânio, Foi Maluf quem fez, Meu nome é Enéas (modelo parafrásico de Meu nome é Avanir), Collor, o caçador de marajás, ACM, a voz da Bahia, entre tantos. Ou até do cultuado Lula lá, que

1. Programa Universidade para Todos 
imita o padrão lingüístico, com igual efeito de ressonância, do famoso I like Ike - slogan do candidato à presidência dos Estados Unidos, Eisenhower, então conhecido como Ike - objeto de longas páginas de Jakobson em seu estudo sobre a função poética da linguagem.

Também alvo de ironias, acusações mordazes e, no mais das vezes, apontamentos críticos superficiais da nossa intelectualidade, é o posicionamento ideológico do governo federal, em distintas épocas, materializado em suas palavras de ordem (Brasil, ame-o ou deixe-o, Pra frente, Brasil!, Integrar para não entregar, dos tempos do milagre econômico; ou Plante que o João garante, do presidente João Figueiredo), ou em assertivas vazias (Nunca fomos tão felizes, do governo Médici; Tudo pelo social, do governo Sarney; Brasil, um país de todos, do governo atual).

Apenas para ultrapassar a crítica epidérmica, não seria exagero afirmarmos que tais plataformas de comunicação não eram só retóricas, mas que seus anunciadores, uma vez governantes, agiram justamente de forma contrária ao seu conteúdo. O que era eufórico no discurso eleitoral se tornou disfórico na ação governamental.

Mas esse é assunto para outro artigo, até porque a complexidade das campanhas políticas extrapola a unidade frasal de seus slogans.

Sem dúvida, há estudos valiosos sobre a propaganda do governo no Estado Novo, nos Cinqüenta anos em cinco da era JK, nos tempos do regime militar e, até mesmo, nas recentes gestões de FHC. E, obviamente, são pesquisas e dissertações feitas a posteriori.

A nossa proposta, ao ocupar este espaço, é discutir um comercial exaustivamente veiculado entre dezembro de 2005 e meados de janeiro de 2006, nos canais de TV nacionais, envolvendo o mundo universitário, do qual estamos próximos pela cátedra. Portanto, uma página no work in progress da estratégia de propaganda do governo Lula.

Centramos nossa reflexão no comercial do ProUni - Programa Universidade para Todos, que transfere recursos públicos da educação a instituições universitárias particulares. Não vamos entrar no mérito do programa em si, criticado pelo seu assistencialismo - por meio dele, o governo compra vagas de universidades privadas (algumas com desempenho medíocre no Provão, que antes media a qualidade de seus serviços), para garantir o acesso ao ensino superior a jovens de classes menos favorecidas. Nosso objetivo é analisar, única e brevemente, os elementos culturais envolvidos na concretização de sua propaganda.

O filme retrata um jovem negro caminhando pelas ruas de uma grande cidade. Aos poucos, ele é seguido por outros estudantes, liderando uma passeata. No plano criativo, e também no da realização cinematográfica, o comercial é, abertamente, uma cópia da atitude de um dos personagens do filme Hair ${ }^{2}$, dirigido por Milos Forman, inspirado numa peça teatral homônima, que se tornou símbolo da cultura hippie norte-americana.

Descartando a questão do plágio, preferimos acreditar que o comercial do conhecimento que tinham do filme de Forman como ponto de partida. No 
entanto, o resultado do jogo intertextual revela uma indiscutível incoerência, já que dialoga com uma peça teatral conhecida pelo seu conteúdo contra o establishment estadunidense, em geral - incluindo o modelo educacional daquele tempo -, e a Guerra do Vietnã, em específico.

O uso de paródias e paráfrases é moeda corrente na criação publicitária, mas quando o discurso se constrói sob as fundações de uma matriz cultural estrangeira, o mínimo que se espera é um diálogo claro e inteligente, capaz de ser compreendido. Ou o resultado é uma conversa deslocada, sem consistência, como o comercial em questão.

O efeito mais danoso das releituras de discursos fundadores, que engrossam o caos identitário contemporâneo, embora elas sejam seminais, é a distorcida interpretação da matriz em que foram inspiradas.

Temos, pois, um produto de comunicação que busca transferir a aura emblemática do movimento pacifista dos hippies ao ProUni, como se este fosse uma cruzada revolucionária. Tanto é assim que, ao fim do comercial, se enuncia a seguinte locução em off:

O ProUni, Programa Universidade para Todos do Governo Federal, já colocou mais de cem mil jovens na faculdade.

O ProUni oferece bolsas gratuitas, ou com cinqüenta por cento de desconto em faculdades particulares em todo o Brasil.

Faça parte dessa revolução na educação brasileira ${ }^{3}$.

Ministério da Educação. Brasil, um país de todos.

E isso sem contar que, numa das cenas do filme, nossos jovens disputam uma partida de basquete - esporte oficial nos Estados Unidos.

Se o comercial reproduz inteiramente a seqüência do filme de Forman, à sua maneira verde-amarela - pois inicia focando a bandeira nacional e termina mostrando um rapaz de costas com a camisa da seleção brasileira de futebol -, é porque reconhece a tradição por ela outorgada, o que pressupõe uma intenção de gerar identificação, de sugerir a semelhança de contextos. Nada mais equivocado. Não há equivalência de valores, em gênero ou em grau, entre os dois momentos.

Mas há outro elemento que torna o comercial do ProUni ainda mais exemplar da prática discursiva incongruente do governo Lula: a sua trilha sonora é a clássica música de Geraldo Vandré, Para não dizer que não falei das flores. Nos trinta segundos que duram a propaganda, ouvimos, num novo arranjo que se afasta da marcha original e envereda por um ritmo claramente americanizado, os versos da primeira estrofe da música e o seu refrão:

Caminhando e cantando e seguindo a canção

Somos todos iguais, braços dados ou não

Nas escolas, nas ruas, campos, construções

Caminhando e cantando e seguindo a canção

Vem, vamos embora, que esperar não é saber,

Quem sabe faz a hora, não espera acontecer

Vem, vamos embora, que esperar não é saber,

Quem sabe faz a hora, não espera acontecer. 
4. MILANEZ, Gabriel. Política pela palavra: um estudo semiótico sobre a comunicação eleitoral do PT nas eleições presidenciais de 1989 e 2002. Trabalho de Conclusão de Curso apresentado ao Departamento de Relações Públicas, Turismo e Publicidade e Propaganda da ECA-USP, em dezembro de 2005, sob minha orientação.

5. GALVÃO, Walnice Nogueira. Saco de gatos. São Paulo: Duas cidades, 1976.

6. O termo ready-made foi cunhado pelo artista plástico Marcel Duchamp para expressar a utilização de um objeto deslocado de seu contexto original, alterando assim seu significado, ou retificando-o. Nós o usamos aqui, por extensão, como todo e qualquer material cultural, no nosso caso uma canção, transposto para outro contexto.
Hino dos militantes da esquerda, cantado em toda e qualquer passeata, a letra convocatória de Vandré ressurge, quase quatro décadas depois, no comercial de um governo capitaneado por um político cujo partido se anunciava, até bem pouco tempo, socialista, e, numa fabulosa metamorfose, parece ter-se tornado mais neoliberal que os neoliberais.

Aliás, o estudo de Gabriel Milanez, sobre a mudança na comunicação do PT nas campanhas eleitorais para a Presidência da República ${ }^{4}$, comprova que os valores estruturantes do discurso petista, na eleição de 1989, articulavam-se no campo do socialismo, com a dominância das palavras operários, oprimidos, burguesia, classe dominante. Já na eleição de 2002, os conectores isotópicos haviam mudado para trabalho, compromisso social, sonho, povo, posicionando o partido não mais como uma organização socialista, disposta a romper com o sistema vigente, mas, sim, adaptada a ele, ainda que atenta aos aspectos sociais da nação.

No propósito de reforçar, ilustrativamente, a igualdade social que o governo Lula defende, enquanto se entoa ao fundo o trecho somos todos iguais, o comercial mostra jovens de várias etnias (negros, mestiços, brancos, amarelos), inclusive deficientes físicos. Ironicamente, ficam de fora da locução as estrofes mais representativas da letra de Vandré:

Pelos campos há fome em grandes plantações

Pelas ruas marchando indecisos cordões

Ainda fazem da flor seu mais forte refrão

E acreditam nas flores vencendo o canhão

Há soldados armados, amados ou não

Quase todos perdidos de armas na mão

Nos quartéis lhes ensinam uma antiga lição

De morrer pela pátria e viver sem razão

Nas escolas, nas ruas, campos, construções

Somos todos soldados, armados ou não

Caminhando e cantando e seguindo a canção

Somos todos iguais, braços dados ou não

Os amores na mente, as flores no chão

A certeza na frente, a história na mão

Caminhando e cantando e seguindo a canção

Aprendendo e ensinando uma nova lição.

Em suma, o que se percebe no plano discursivo nesta peça publicitária do atual governo, com o emprego descontextualizado da letra de Vandré, é a mesma inabilidade e o mesmo descompasso de sua prática política.

O mais patético, vale ressaltar, é que a incensada letra de Vandré, conforme conclusão de Walnice Nogueira Galvão, em seu já clássico ensaio MPB: uma análise ideológica ${ }^{5}$, não propunha, e continua sem propor, nenhuma mobilização real, a não ser cantar, representando a resignação de uma parte da nossa classe média intelectualizada.

A desinformação parece ser, portanto, outro dos males que acometem os comunicólogos do governo Lula.

E a utilização de tal canção como um ready-made ${ }^{6}$, aproveitando a sua carga histórica, mostra-nos, novamente, que toda boa releitura é, antes de tudo, uma prova de compreensão do real significado de sua matriz cultural. 
As duas linhas de forças que sustentam o comercial do ProUni, a estilização da seqüência de Hair e o uso enviesado da música de Vandré denotam uma grave miopia comunicativa, pois pior do que a citação pela citação é a citação sem cabimento.

Esse exemplo de propaganda estatal nos lembra um trecho do romance Extensão do domínio da luta, de Michel Houellebecq, em que o protagonista, entrando na Nova Galeria em Rouen, vê, enquanto faz supermercado, um homem no chão cercado por várias pessoas. No fim da compra, ele se inteira de que o homem morreu, ao som de um jingle cujo refrão diz: Nova Galeria, hoje... Cada dia é um novo dia ${ }^{7}$.

Indubitavelmente, cada dia é um novo dia na comunicação do Estado com os cidadãos. Mas todo novo dia vem de um dia anterior, e não se pode construir bem o futuro reencenando um passado mal entendido.

A idéia subjacente a esse comercial nos remete ainda à cena da Challenger explodindo nos ares após seu lançamento, em 1986, enquanto o locutor da Nasa em off, com segundos de atraso, dizia que estava tudo bem com a nave.

Da mesma forma, caminhando e cantando com essa comunicação, o governo federal mostra a sua falta de sintonia com a realidade cultural do País.

Resumo: $O$ artigo comenta a falta de críticas regulares da classe intelectual ao conteúdo de campanhas publicitárias veiculadas em televisão no Brasil, em especial às propagandas do governo. Como contribuição, o autor analisa os principais elementos culturais que se cruzam incoerentemente no comercial do ProUni - Programa Universidade para Todos, do Ministério da Educação: a citação de uma seqüência do filme Hair e a trilha sonora que reproduz parte da canção "Para não dizer que não falei das flores", de Geraldo Vandré. A conclusão é de que esse filme publicitário retrata perfeitamente a própria, e equivocada, concepção de comunicação do governo Lula.

Palavras-chave: propaganda estatal, ProUni, governo Lula, televisão, intertextualidade.
Abstract: This paper comments on the regular criticism posed by intellectuals to the content of publicity campaigns shown by television in Brazil and, specially, government campaigns. As a contribution, the author analyzes the main cultural elements incoherently intertwined in the ProUni commercial: Programa Universidade para Todos (Program University for Everyone), by the Education Ministry of Brazil. In his view, these elements are: the quotation of a sequence from the film Hair and the soundtrack which reproduces part of the song "Para não dizer que não falei de flores", by Geraldo Vandré. The author concludes that the publicity film in question perfectly mirrors the very mistaken conception of communication in the present Lula administration.

Keywords: state propaganda, ProUni, Lula government, television, intertextuality.
7. HOUELLEBECQ, Michel. Extensão do domínio da luta. Porto Alegre: Sulina. 2002. 